\title{
MIGRACIONES LABORALES ENTRE ESPAÑA Y AMERICA. LA PROCEDENCIA DE MARINEROS EN LA CARRERA DE INDIAS, 1598-1610
}

\author{
POR \\ AUKE P. JACOBS \\ Universidad Católica. Nimega
}

La creciente importancia comercial de las Indias durante la primera mitad del siglo XVI provocó un aumento del número de navíos españoles hacia el Nuevo Mundo y consecuentemente este alza, a su vez, aumentó la demanda de marineros. Este flujo de migración laboral entre España y América no sólo es importante por su impacto sobre las regiones donde se reclutaron los marineros, sino también por la transformación parcial en inmigración permanente en las Indias. Ambos aspectos vamos a estudiarlos en este breve ensayo para los años de 1598 a 1610, basándonos en las listas de marineros que contienen los Registros de Ida de la Casa de Contratación (1). A los abandonos de los marineros añadimos también Ios de los soldados de los galeones, para aproximar la importancia de esta inmigración para las Indias.

El paulatino aumento de demanda de marineros hasta 1586 es difícil de conocerlo por la pobreza de documentos al respecto. De 1492 a 1586 se ha podido identificar la procedencia de un total de 3.963 marineros. Estos datos, a pesar de ser escasos, ya muestran un fuerte dominio de andaluces, un 48 por 100, procedente principalmente del Reino de Sevilla, en lo que hoy son las provincias de Cádiz, Huelva y Sevilla. Sin embargo existe un alto número de marineros sin procedencia identificada en total 495,0

Sigla utilizada:

AGI: Archivo General de Indias. Sevilla.

(1) AGI. Contratación, legs. 1130-1156B, 1802 y 1804. 
sea el 14 por 100. La segunda región en importancia está formada por el País Vasco seguida por el Reino de Galicia. Entre los extranjeros destacan los portugueses y los italianos (2).

Para la época que estudiamos hemos podido localizar dentro de los ya mencionados Registros de Ida las listas de marineros de 202 naos mercantes, que representan algo más que la cuarta parte del total de los 759 barcos identificados (3). El número de marineros asciende a un total de 9.524. La distribución de las listas durante los años de 1598/1610, sin embargo, es bastante desigual pues van desde sólo tres naos en 1602 hasta 42 para el año de 1608 (4). A pesar de esta limitación estas listas nos ofrecen una imagen bastante representativa de la procedencia de los marineros en la carrera de Indias durante esta época.

En teoría, la tripulación sólo podía estar formada por españoles. Encontramos disposiciones que exigían que el contramaestre sólo podría ser extranjero si estaba casado con una española y otras que prohibían alistar marineros extranjeros. Para evitar que la relativa escasez de marineros de procedencia española se volviera crónica, no se admitían extranjeros como grumetes y pajes, porque de esta forma impedían a los propios españoles obtener los conocimientos necesarios para llegar a ser marineros en la carrera de Indias (5). Empero estas prohibiciones no podían evitar que la realidad impusiera sus propios criterios.

Generalmente se supone que hubo grandes problemas para tripular a las naos de la Carrera de Indias con marineros españoles. Esta suposición proviene, sobre todo, de los documentos coetáneos que permiten la inclusión de extranjeros entre los

(2) Francisco de ESPÓSITO: "Navegazione atlantica ed emigrazione: La provenienza dei marineri impegrati nella Carrera de Indias (1492-1588)". Atti del V Convegno Internazionale di Studi Colombini "Navi e navigazione nei sécoli XV e XVI", Genova, 1990, I, págs. 321-349.

(3) Huguette y Pierre Chaunu: Séville et l'Atlantique (1504-1650), vol. IV (Le trafic de 1596 a 1620), París, 1958, págs. 50-323.

(4) Este año de 1608 también incluye a las naos que inicialmente tenían que salir en 1607, pero que no lo hicieron por la presencia de una flota holandesa cerca de Cádiz.

(5) José de Veitia Linaje: Norte de la Contratación de las Indias. Lib. I, Edición e introducción de Francisco de Solano. Madrid. Ministerio de Hacienda, págs. 241-242, 1981. 
tripulantes por la falta de marineros españoles (6). Puede ser que esta suposición tenga validez para el conjunto de las naos mercantes y de guerra españolas que navegaban en el Mediterráneo y el Mar del Norte, aunque carecemos de datos sobre la composición geográfica de las tripulaciones al respecto. Para la Carrera de Indias no existe una escasez marinera española que se pueda cualificar como excepcional; por lo menos, por los datos que disponemos para los años de 1598 a 1610 no lo confirman. Si se tenían que tripular las naos mercantes de las flotas a Indias durante estos años sólo con marineros españoles, se llegaría a una proporción de un marinero por cada 7,5 toneladas. Con la participación extranjera se llega a una proporción de un marinero por cada 5,7 toneladas, es decir, ligeramente por encima la norma oficial de un marinero por cada 5,6 toneladas (7). La distribuicion por año de esta norma fluctúa entre 4,4 durante los años 1598 y 1600 hasta llegar a su cuota máxima de 7,4 en 1604 , probablemente debida a las inclemencias del tiempo y la consiguiente mala cosecha de este año (8).

De los 9.524 marineros identificados sólo 961 provienen de fuera de la Península: con la adición que no hemos podido

(6) Ferdinand BRAUDEL: The Mediterranean and the Mediterranean Worldin the Age of Philip II. Glasgow, 1978, vol. I, págs. 138-140 y 146. AGI, Contratación, leg. 1 30, incluye una real cédula del 22 de julio de 1598 que permite la inclusión de marineros extranjeros para evitar que la flota se retrase. Otra referencia de este tipo encontramos en una real cédula expedida en El Pardo el 16 de noviembre de 1607, que se cita en la visita a la nao de Sebastián de Pineda cuando se menciona que "no embargante que en ella aya alistados algunos marineros estranxeros destos rreinos por la falta que ay en ellos e naturales, su magestad, fue servido de permitir por esta vez se abilitasen los dichos estrangeros en esta nao y en las demás de esta presente flota"... AGI, Contratación, leg. $1151 \mathrm{~A}$. En una carta de los oficiales reales de la Casa de Contratación a Felipe Manrique en Sanlúcar de Barrameda del 19 de mayo de 1609 se le advierte: "que alistados en la flota no los tomaran para la harmada y en caso que no se pueda escusar estrangeros en que V.m. andeis con gran cuydado rrecibir a levantiscos, alemanes, portugueses y destos los menos que ser posible"... AGI, Contratación, leg 1154B. Cédulas y cartas de esta indole se puede encontrar por todas partes. La práctica, sin embargo, hizo imposible el prescindir de extranjeros entre los marineros de la Carrera de Indias.

(7) Carla Rahn Phillips: Six Galleons for the King of Spain. Imperial Defense in the Early Seventeenth Century. Baltimore, Londres, 1986, pág. 140. Para los años 1598-1610 tenemos 9.524 marineros para un total de 54.507 toneladas. Para los diferentes años esta relación de un marinero por cada 5,6 toneladas se puede variar de un marinero por cada 4,4 tonelada en 1600 hasta un marinero por cada 7,4 tonelada en 1604.

(8) Parece que las tripulaciones de los galeones de la Armada de la Guardia de la Carrera de Indias también cumplieron esta norma oficial de un marinero por cada 5,6 toneladas. Por lo menos la Armada de 1601, capitán-general Luis Fajardo, consistió de siete galeones y 4 pataches, en total 3.787 toneladas, con una tripulación de 732 marineros. Chaunu [3], pág. 122. 


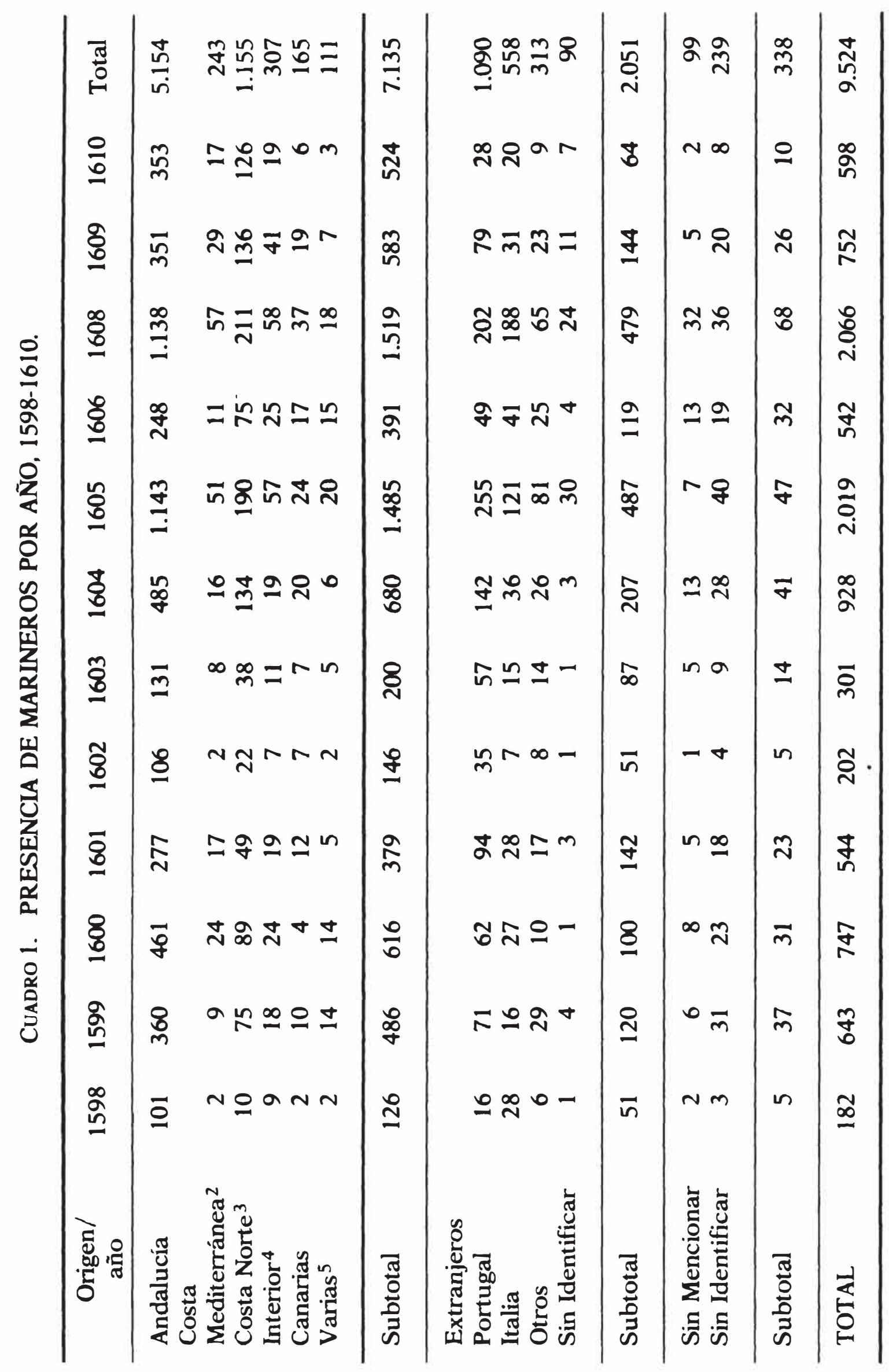




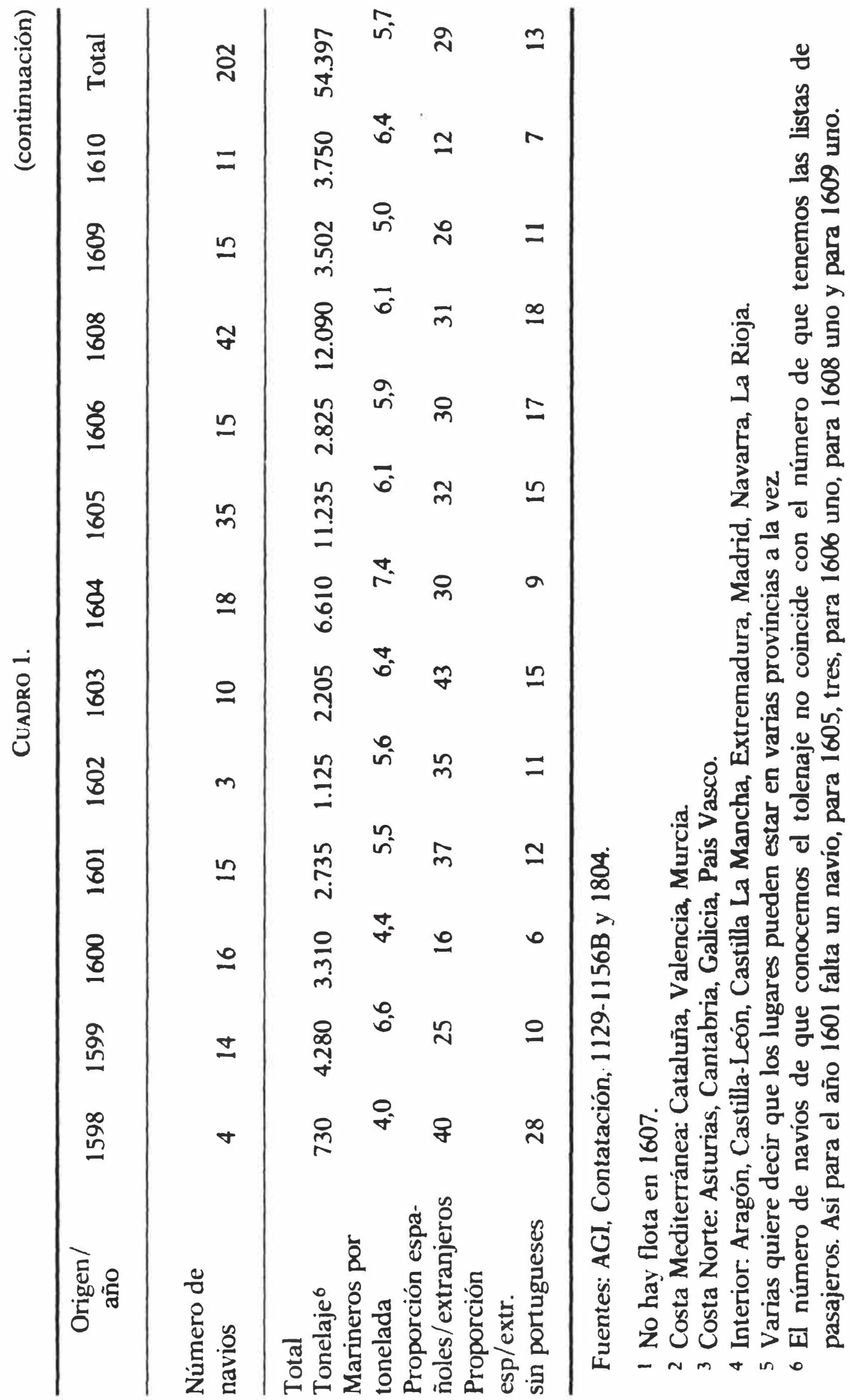

R. I., 1991, n 193 
identificar la procedencia de 428 marineros, es decir un escaso 4,5 por 100 del total. Si incluimos a los portugueses dentro de los extranjeros llegamos a un total de 2.051 marineros. Los portugueses se consideraron como extranjeros a pesar de la unión de las dos Coronas en 1580 (9). El número total de los portugueses es el segundo en importancia detrás de Andalucía. Casi el 70 por 100 de estos portugueses vienen de la región del Algarve. Desde el punto de vista del reclutamiento de marineros el Algarve se comportaba como parte integral del mercado laboral del que se aprovechaba la Carrera de Indias.

\section{LAS CARACTERÍSTICAS DEL MERCADO LABORAL}

Cuando tomamos en cuenta el origen de los marineros españoles vemos que la atracción de la Carrera de Indias en Andalucía se limitaba a muy pocas ciudades y lugares, casi todos situados entre Gibraltar y Ayamonte. En la provincia la Carrera no desempeñó una gran atracción. De la provincia de Sevilla vienen en total 1.925 marineros; de los cuales 1.778 proceden únicamente de Sevilla y Triana. En la provincia de Huelva cinco núcleos urbanos - Ayamonte, Cartaya, Huelva, Lepe y Moguer- son responsables de más del 90 por 100 de los marineros; entre los cuales destaca Ayamonte con un total de 977. Y en la provincia de Cádiz proveen Cádiz, Puerto de Santa Mairía y Sanlúcar de Barrameda 860 marineros sobre un total de 986.

La jerarquía establecida entre los tripulantes la hemos agrupado de siguiente forma: oficiales (maestre, contramaestre, piloto y capitán), suboficiales (calafate, carpintero, cirujano-barbero, despensero y escribano), artilleros (condestable, artillero), marineros, grumetes y pajes.

Casi un 90 por 100 de la tripulación andaluza procede sólo de diez lugares diferentes, que a su vez forma casi la mitad de toda la tripulación marinera. Entre estos lugares existe una jerarquía bastante acusada. La ciudad de Sevilla y su barrio afin de Triana

(9) En un pleito contra los marineros portugueses Melchor Alfonso, Domingo Martín, Diego Alonso Sierra y Manuel Montero por haberse alistado en 1604 en la nao "Nuestra Señora de la Candelaria" del maestre Francisco Sánchez de Ortega siendo portugueses, alegan en su defensa que no habían cometido delito alguno porque "no somos Portugueses sino del Algarve y los del Algarbe pueden yr e venir por marineros e así emos ydo y venido muchas bezes como si es [sic] necesario. Parecerá por las listas de las naos en que avemos ydo" A pesar de esta defensa se les condenó a 3.000 maravedis cada uno. AGI, Contratación, leg. 69B, Ramo 1, $\mathrm{n}^{2} 2$. 
son los que ocupan mayoritariamente los puestos de mando: oficiales, suboficiales, condestables y artilleros. La provincia de Huelva ocupa el lugar preferente para los marineros y grumetes, mientras que de Sevilla y Triana juntos procede el mayor número de pajes. La provincia de Cádiz ocupa un lugar intermedio entre las dos anteriores. La contribución de las demás provincias andaluzas es, en comparación, más bien simbólica.

CUADRO 2. PROCEDENCIA DE MARINEROS ANDALUCES.

\begin{tabular}{|c|c|c|c|c|c|c|c|}
\hline $\begin{array}{c}\text { Rango/ } \\
\text { Procedencia } \\
\end{array}$ & Of. & Subof. & Artil. & Marin. & Grum. & Pajes & Total \\
\hline \multicolumn{8}{|l|}{ Cádiz } \\
\hline $\begin{array}{l}\text { Cádiz } \\
\text { Puerto de }\end{array}$ & 35 & 24 & 20 & 80 & 53 & 45 & 257 \\
\hline $\begin{array}{l}\text { Sta. María } \\
\text { Sanlúcar de }\end{array}$ & 21 & 28 & 10 & 91 & 115 & 32 & 297 \\
\hline Barrameda & 29 & 18 & 17 & 92 & 96 & 54 & 306 \\
\hline Otras & 5 & 6 & 4 & 16 & 59 & 36 & 126 \\
\hline Subtotal & 90 & 76 & 51 & 279 & 323 & 167 & 986 \\
\hline \multicolumn{8}{|l|}{ Huelva } \\
\hline Ayamonte & 62 & 24 & 15 & 392 & 347 & 137 & 977 \\
\hline Cartaya & 4 & - & 1 & 39 & 77 & 14 & 135 \\
\hline Huelva & 9 & 6 & 2 & 94 & 113 & 21 & 245 \\
\hline Lepe & 3 & 8 & 4 & 65 & 89 & 18 & 187 \\
\hline Moguer & 13 & 6 & 4 & 64 & 93 & 34 & 214 \\
\hline Otras & 3 & 4 & 5 & 24 & 84 & 47 & 167 \\
\hline Subtotal & 94 & 48 & 31 & 678 & 803 & 251 & 1.905 \\
\hline \multicolumn{8}{|l|}{ Sevilla } \\
\hline Sevilla & 160 & 99 & 45 & 104 & 217 & 261 & 886 \\
\hline Triana & 132 & 194 & 40 & 239 & 186 & 120 & 911 \\
\hline Otras & 1 & 11 & 4 & 14 & 66 & 54 & 150 \\
\hline Subtotal & 293 & 304 & 89 & 357 & 469 & 435 & 1.947 \\
\hline Otras provincias & 9 & 8 & 31 & 69 & 102 & 97 & 316 \\
\hline TOTAL & 486 & 436 & 202 & 1.383 & 1.697 & 950 & 5.154 \\
\hline
\end{tabular}

Fuentes: AGI, Contratación, 1129-1156B y 1804.

1 Of. = Oficiales; Subof. = Suboficiales; Artil. = Artilleros; Marin $=$ Marineros; Grum. $=$ Grumetes. 
Este reducido mercado laboral que disponía la Carrera de Indias en Andalucía se podía completar, sólo en parte, por tripulantes de otras regiones españolas. La única región que se puede comparar con Andalucía es el País Vasco, cuya presencia en todos los eslabones es comparable a la de Cádiz. Galicia y Cataluña siguen a gran distancia. La relativa ausencia de asturianos y santanderinos se debe presumiblemente a la mortandad ocasionada por la epidemia de la peste negra, que entró por esta zona ya en 1596. Lo que si salta a la vista es que las provincias interiores de Castilla contribuyen con un mayor número de tripulantes que toda la costa mediterránea. El único rango en que los catalanes alcanzan una mayor cota que los castellanos del interior es entre los marineros. La presencia de los canarios entre los tripulantes está infravalorada porque todas las naos, de que tenemos datos, salieron de Sanlúcar de Barrameda o Cádiz.

CUADRo 3. PROCEDENCIA DE MARINEROS ESPAÑOLES (SIN ANDALUCIA) POR RANGO, 1598-1610

\begin{tabular}{|c|c|c|c|c|c|c|c|}
\hline $\begin{array}{c}\text { Rango/ } \\
\text { Procedencia }\end{array}$ & Of. & Subof. & Artil. & Marin. & Grum. & Pajes & Total \\
\hline \multicolumn{8}{|l|}{ Costa Norte } \\
\hline Asturias & 3 & 2 & 5 & 20 & 16 & 7 & 53 \\
\hline Cantabria & 2 & 8 & 6 & 23 & 23 & 5 & 67 \\
\hline Galicia & 5 & 6 & 8 & 72 & 96 & 28 & 215 \\
\hline País Vasco & 70 & 95 & 54 & 274 & 218 & 109 & 820 \\
\hline Subtotal & 80 & 111 & 73 & 389 & 353 & 149 & 1.155 \\
\hline \multicolumn{8}{|l|}{ Interior } \\
\hline Aragón & 1 & 1 & - & 6 & 7 & 3 & 18 \\
\hline $\begin{array}{l}\text { Castilla-León } \\
\text { Castilla La }\end{array}$ & 7 & 16 & 9 & 6 & 32 & 26 & 96 \\
\hline Mancha & 1 & 9 & 7 & 7 & 16 & 15 & 55 \\
\hline Extremadura & 1 & 12 & 4 & 8 & 33 & 23 & 81 \\
\hline Madrid & 2 & 6 & 1 & 1 & 10 & 8 & 28 \\
\hline Navarra & 一 & - & 2 & 3 & 10 & 4 & 19 \\
\hline La Rioja & 1 & 2 & 1 & - & 4 & 2 & 10 \\
\hline Subtotal & 13 & 46 & 24 & 31 & 112 & 81 & 3307 \\
\hline
\end{tabular}


Cuadro 3.

(continuación)

\begin{tabular}{|c|c|c|c|c|c|c|c|}
\hline $\begin{array}{c}\text { Rango/ } \\
\text { Procedencia }\end{array}$ & Of. & Subof. & Artil. & Marin. & Grum. & Pajes & Total \\
\hline $\begin{array}{l}\text { Costa } \\
\text { Mediterránea }\end{array}$ & & & & & & & \\
\hline $\begin{array}{l}\text { Cataluña } \\
\text { Murcia } \\
\text { Valencia }\end{array}$ & $\begin{array}{l}11 \\
-\end{array}$ & $\begin{array}{r}12 \\
2 \\
4\end{array}$ & $\begin{array}{r}14 \\
1 \\
4\end{array}$ & $\begin{array}{r}97 \\
5 \\
8\end{array}$ & $\begin{array}{r}57 \\
7 \\
5\end{array}$ & $\begin{array}{r}14 \\
1 \\
1\end{array}$ & $\begin{array}{r}205 \\
16 \\
22\end{array}$ \\
\hline Subtotal & 11 & 18 & 19 & 110 & 69 & 16 & 243 \\
\hline Canarias & 32 & 14 & 6 & 82 & 38 & 13 & 165 \\
\hline Varias 1 & 7 & 14 & 4 & 22 & 50 & 14 & 111 \\
\hline TOTAL & 143 & 203 & 126 & 614 & 622 & 273 & 1.981 \\
\hline
\end{tabular}

Fuentes: AGI, Contratación, 1129-1156B y 1804.

1 Varias: Lugares y pueblos que pueden estar en más de una provincia por carecer de una indicación más precisa.

El monopolio sevillano en el tráfico marítimo con las Indias y las características mismas de la navegación atlántica provocó esta desigualdad entre las procedencias de los tripulantes españoles. Cuando los andaluces no llegaban a tripular las naos, se tenía que recurrir a marineros de regiones tan distantes como el País Vasco, Galicia o Cataluña. De esta circunstancia se aprovecharon, sobre todo, los portugueses de la provincia vecina de Huelva, el Algarve, y en menor medida los de las zonas más nórdicas, que además disponían de gran experiencia en la navegación atlántica. Del Algarve procedían más del 75 por 100 de todos los portugueses. Los italianos, el segundo grupo en importancia entre los extranjeros, proceden en su mayoría de las regiones vecinas de Génova y Saboya.

La participación extranjera durante los años de 1598-1610 llega a un 22,3 por 100 del total, excluyendo a aquéllos de los que desconocemos la procedencia. Si miramos más detenidamente esta participación por año, muestran las cifras que la Carrera de Indias tuvo una menor atracción para los extranjeros de fuera de la Península durante los años de 1599 a 1602, los años de la gran epidemia de peste, con el mínimo en 1600 
alcanzando sólo el 5,3 por 100 del total. El año 1605 es el primer año en que los extranjeros ocupan más del 10 por 100 de la tripulación, es decir, 11,1 por 100; en 1606 recae de nuevo por bajo de 10 por 100 para volver a esta cifra de nuevo en 1609 . El año con mayor porcentaje de extranjeros es 1608 con 14,4 por 100 (10). Tanto el año 1605 como 1608 se veían precedidos por años en que no había flotas, que seguramente influyó en estos porcentajes altos de participación extranjera. Pues no son cifras que muestran una gran escasez de marineros españoles salvo cuando incorporamos a los portugueses entre los extranjeros llegamos a cifras más importantes. También muestra el cuadro I que en el reclutamiento de los extranjeros existe una gran preferencia por los que proceden de las costas atlánticas $y$, por consiguiente, una menor incidencia de los marineros procedentes del Mediterráneo, con la excepción de italianos. La atracción de la Carrera de Indias para los extranjeros se vio, pues, bastante afectada durante la epidemia de peste que asoló a Andalucía durante 1599-1602 y favorecida durante los años 1605 y 1608 en que se pretendió recuperar la ausencia de flotas en los años precedentes.

La distribución entre españoles y extranjeros en los diferentes eslabones de la jerarquía muestra - sin incluir a los que cuya procedencia no hemos podido identificar, pero sí a los portugueses- que la mayor incidencia de los extranjeros se produce entre los marineros, artilleros y grumetes con respectivamente $39,8,37,7$ y 34,5 por 100 . Entre los oficiales y pajes encontramos el menor número de extranjeros, representando respectivamente el 7,8 y el 14,9 por 100 del total. Los suboficiales forman el grupo intermedio con una presencia de 20,8 por 100 de extranjeros, entre los que destacan los italianos. Los portugueses constituyen el grupo de extranjeros con la mayor presencia en todos los eslabones, con la excepción de los suboficiales y los artilleros. Entre los artilleros destacan los alemanes (11). Podemos concluir que la preferencia al recurrir a extranjeros entre los tripulantes recayó sobre los portugueses y en menor medida sobre los italia-

(10) En 1604 no hubo flota a Tierra Firme mientras que las naos que tenían que salir en 1607 no lo hicieron por la presencia de la ya mencionada flota holandesa en el Estrecho para aparecer entre las naos de 1608. De esta forma hemos juntado las listas de marineros de 1607 con los de 1608 . Véase también Chaunu, [3], págs. 178-179 y 230-235.

(11) Auke P. JACOBS: "Marineros flamencos en la Carrera de Indias, 15981610", Foro Hispánico, (1992): 3, en prensa. En este artículo se trata más ampliamente la posibilidad de que parte de los marineros alemanes proceda, en realidad, de los Países Bajos. 
nos. Además estos extranjeros tenían más posibilidad de alistarse en las flotas de la Carrera de Indias en los rangos de marineros y grumetes, por ser los rangos que más personal requería. Sólo excepcionalmente podían ocupar los puestos de mando. Al parecer, influyó también en la admisión de extranjeros si provenían de países incorporados a la Corona española o de naciones de su esfera de influencia.

CUADRo 4. PROCEDENCIA DE MARINEROS EXTRANJEROS POR RANGO, 1598-1610

\begin{tabular}{|c|c|c|c|c|c|c|c|}
\hline $\begin{array}{c}\text { Rango/ } \\
\text { Procedencia }\end{array}$ & Of. & Subof. & Artil. & Marin. & Grum. & Pajes & Total \\
\hline $\begin{array}{l}\text { Europa del } \\
\text { Nortel }\end{array}$ & - & 6 & 63 & 82 & 28 & 8 & 187 \\
\hline $\begin{array}{l}\text { Europa } \\
\text { Central }\end{array}$ & - & - & 2 & 5 & 1 & - & 8 \\
\hline $\begin{array}{l}\text { Mediterráneo } \\
\text { Italia } \\
\text { Otros }^{3}\end{array}$ & $\begin{array}{r}12 \\
2\end{array}$ & $\begin{array}{r}63 \\
5\end{array}$ & $\begin{array}{r}41 \\
5\end{array}$ & $\begin{array}{r}270 \\
24\end{array}$ & $\begin{array}{r}165 \\
11\end{array}$ & $\begin{array}{l}7 \\
-\end{array}$ & $\begin{array}{r}558 \\
47\end{array}$ \\
\hline Subtotal & 14 & 68 & 46 & 294 & 176 & 7 & 605 \\
\hline Portugal & 30 & 49 & 11 & 380 & 496 & 124 & 1.090 \\
\hline $\begin{array}{l}\text { Indias } \\
\text { españolas } \\
\text { Indias portuguesas }\end{array}$ & $\frac{9}{-}$ & $\frac{8}{-}$ & 1 & $\frac{15}{-}$ & $\begin{array}{r}14 \\
4\end{array}$ & $\frac{10}{-}$ & $\begin{array}{r}57 \\
4\end{array}$ \\
\hline Subtotal & 9 & 8 & 1 & 15 & 18 & 10 & 61 \\
\hline $\begin{array}{l}\text { Indios } \\
\text { Negros } \\
\text { Esclavos }\end{array}$ & $\begin{array}{l}\overline{-} \\
-\end{array}$ & $\overline{1}$ & $\begin{array}{l}- \\
-\end{array}$ & $\begin{array}{r}- \\
4 \\
6\end{array}$ & $\begin{array}{l}\overline{10} \\
51\end{array}$ & $\begin{array}{r}1 \\
3 \\
13\end{array}$ & $\begin{array}{r}1 \\
18 \\
71\end{array}$ \\
\hline Subtotal & - & 2 & - & 10 & 61 & 17 & 90 \\
\hline TOTAL & 53 & 133 & 123 & 786 & 780 & 166 & 2.051 \\
\hline
\end{tabular}

Fuentes: AGI, Contratación, 1129-1156B y 1804.

1 Europa del Norte (por orden de importancia): Alemania, Flandes, Dinamarca, Escocia, Noruega, Irlanda, Islandia y Suecia.

2 Europa Central (por orden de importancia): Polonia y Rumania.

3 Los otros países del Mediterráneo (por orden de importancia): Francia, Grecia, Yugoslavia, Malta y Egipto. 
Resulta evidente, como ya hemos dicho, que la procedencia de regiones de alguna costa atlántica era valorada positivamente. Entre los españoles mismos resulta aún más importante porque los tripulantes procedentes de las costas mediterráneas españolas representan algo más de un 3 por 100, mientras que entre los extranjeros representan un 29,5 por 100 . La escasa participación de catalanes se debe principalmente a su falta de experiencia de navegar en alta mar. La mayor parte del comercio se limitó a las costas del propio principado y Rosellón mientras que el comercio de ultramar no iba más lejos de Cerdeña, Sicilia e Italia (12).

Durante la época que estudiamos, los marineros, grumetes y pajes ganaban respectivamente $1.500,1.000$ y 750 maravedís al mes cuando estaban en la mar y los artilleros 1.875 maravedís, un nivel que sus salarios ya habían alcanzado en 1567 y que no se cambió hasta por lo menos 1623 . A esta constancia salarial de estos tripulantes tenemos que añadir que durante el viaje recibían sus raciones diarias de comida. De esta forma el salario de los tripulantes creció intrínsicamente más que de los que sólo dependían de un salario, tomando en cuenta la paulatina, pero continua, subida de precios durante estos años (13). A pesar de esta ventaja sobre los salarios de los que trabajaban en tierra en profesiones comparables, parece que no fue un factor de atracción para los marineros de las zonas mediterráneas españolas y sí en mayor medida para los extranjeros procedentes de los demás países del norte del Mediterráneo, aunque carecemos de datos sobre los sueldos de marineros italianos. La presencia extranjera relativamente escasa, en general, durante estos años parece más bien debida a la crisis de los años de 1600 a 1605. Así el afán de marineros españoles para prestar servicio en la carrera de Indias fue mayor que en circunstancias normales.

(12) John H. Elliot, The Revolt of the Catalans. A Study in the Decline of Spain. 1598-1640 (Cambridge, 1984) pág. 54.

(13) Earl J. Hamilton: "Pago y alimentación en las flotas de Indias (15031660)", en El Florecimiento del Capitalismo (Madrid, 1984), págs. 117-122. 
CuAdro 5-A LOS MARINEROS ANDALUCES POR EDADES, 1598-1810

\begin{tabular}{crrrrr}
\hline Origen/Edades & Cádiz & Huelva & Sevilla & Otras & Total \\
\hline 10 & 1 & - & 6 & - & 7 \\
$10-15$ & 151 & 198 & 331 & 69 & 749 \\
$16-20$ & 288 & 702 & 489 & 116 & 1.595 \\
$21-25$ & 205 & 441 & 378 & 54 & 1.078 \\
$26-30$ & 146 & 227 & 245 & 36 & 654 \\
$31-35$ & 54 & 76 & 91 & 15 & 236 \\
$36-40$ & 44 & 100 & 101 & 13 & 258 \\
$41-45$ & 9 & 21 & 21 & 1 & 52 \\
$46-50$ & 17 & 29 & 38 & 1 & 85 \\
$51-55$ & 2 & 10 & 3 & - & 15 \\
$56-60$ & 4 & 4 & - & - & 8 \\
$>60$ & 1 & - & - & - & 1 \\
Desc. & 64 & 97 & 244 & 11 & 416 \\
\hline TOTAL & 986 & 1.905 & 1.947 & 316 & 5.154 \\
\hline
\end{tabular}

Fuente: AGI, Contratación, 1129-1156B y 1804.

CUADRO 5-B. LOS MARINEROS VASCOS, PORTUGUESES E ITALIANOS POR EDADES, 1596-1610

\begin{tabular}{|c|c|c|c|c|c|}
\hline Origen & País Vasco & $\begin{array}{l}\text { Portugal } \\
\text { Algarve }\end{array}$ & $\begin{array}{c}\text { Portugal } \\
\text { Otras }\end{array}$ & Italia & Total \\
\hline \multicolumn{6}{|l|}{ Edad } \\
\hline$<10$ & - & 1 & - & - & 1 \\
\hline $10-15$ & 59 & 63 & 30 & 10 & 162 \\
\hline $16-20$ & 223 & 316 & 120 & 101 & 760 \\
\hline $21-25$ & 221 & 175 & 78 & 164 & 638 \\
\hline $26-30$ & 143 & 103 & 50 & 152 & 448 \\
\hline $31-35$ & 48 & 24 & 13 & 51 & 136 \\
\hline $36-40$ & 31 & 36 & 21 & 46 & 134 \\
\hline $41-45$ & 7 & 9 & 4 & 11 & 31 \\
\hline $46-50$ & 13 & 6 & 2 & 14 & 35 \\
\hline $51-55$ & 1 & 1 & - & 1 & 3 \\
\hline $56-60$ & 1 & 2 & - & 1 & 4 \\
\hline$>60$ & 1 & - & - & - & 1 \\
\hline Desc. & 72 & 25 & 11 & 7 & 115 \\
\hline TOTAL & 820 & 761 & 329 & 558 & 2.468 \\
\hline
\end{tabular}

Fuente: AGI, Contratación, 1129-1156B y 1804. 
La oferta de mano de obra se sitúa entre hombres de 16 a 30 años, sobre todo, en el grupo de 16 a 20 y de 21 a 25 . Es decir, el grupo de edad de donde se solían reclutar los grumetes y los marineros. Si comparamos esta estructura por edades de los tripulantes andaluces con las zonas con mayor participación entre las tripulaciones, como País Vasco, Portugal -dividida en la zona del Algarve y las demás regiones- e Italia veremos que la atracción de la Carrera de Indias recae tanto para el País Vasco como para el Algarve sobre el grupo de edades comprendidos entre los 16 a 30 años. Para las otras regiones de Portugal los de 16 a 20 años es el grupo de mayor importancia. Para Italia es el grupo de 21 a 30 años quien tiene el mayor peso, seguramente debido a que los italianos son los que tiene mayor presencia entre los suboficiales.

El intento de reservar en exclusiva a españoles los rangos de marinero y grumete no concuerda con las posibilidades del mercado laboral. No hay que olvidar que disponemos sólo de una cuarta parte escasa del total de naos que salieron durante estos años. El peso de la Carrera de Indias en el mercado laboral local para individuos entre los de 16 a 25 años podemos aproximarlo al multiplicar nuestros datos con un factor cuatro. A esta aproximación hay que añadir además la tripulación de los galeones de la Armada de Guardia y los soldados, preferentemente reclutados cerca de Sevilla para evitar gastos adicionales de un traslado largo (14), pudiéndose estimar en, aproximadamente, otros 2.000 hombres. Podemos concluir que este número de marineros y soldados necesario para tripular las flotas a las Indias sobrepasó las posibilidades del mercado laboral en Andalucía. La relativa escasez de españoles sólo se podía subsanar mediante el alistamiento de extranjeros.

(14) Al parecer ya no podían limitarse a Andalucía para reclutar los soldados. Al menos en 1606, Don Diego de Orduña, comisario de infantería encargado del reclutamiento de soldados para la Armada de Guardia en Extremadura y Ciudad Rodrigo, AGI, Contratación, leg. 598, n² 2, Ramo 1, n² 4. 


\section{LAS AUSENCIAS EN LAS INDIAS (15)}

La política demográfica de las Indias, según el «modelo» desarrollado por los Austrias, tenía como fin poblar las Indias con individuos de probada ortodoxia cristiana que además cumplían los siguientes requisitos: la emigración a las Indias era necesaria por razones laborales, es decir, funcionarios y eclesiásticos, con sus respectivos séquitos de criados, así como mercaderes; o se hizo para reunirse con familiares que garantizaran ayuda durante los primeros tiempos de su estancia en el Nuevo Mundo. Esta política fracasó, en gran medida, por las migraciones laborales que provocaba la Carrera de Indias. Aunque los tripulantes de las flotas tenían que limitar su estancia en las Indias al tiempo que las flotas estaban en sus puertos, muchos preferían quedarse. Los documentos nos hablan de un creciente número de marineros y soldados ausentes. Para los marineros es más difícil averiguar si la ausencia correspondía de veras a un deseo de quedarse o que era más bien eventual. Es sabido que en cada flota se componía de un número de navios que servían para «echar al través", es decir, que eran desguazados para la reparación de las demás naos. Oficialmente los marineros de estos barcos se ténian que repartir entre los demás. Resulta, sin embargo, que esto no siempre sucedió de este modo, fuera intencionadamente o no. Por otra parte, desaparecen marineros de las listas para aparecer en las listas de otras naos, a veces de las flotas del año siguiente. Esto hace muy difícil averiguar con cierta base el número de marineros ausentes de las naos mercantes. Los datos, que nos proporcionan la ausencia de los tripulantes de galeones de la Armada de Indias, son menos problemáticos para averiguar el número total de marineros y soldados implicados.

En 1601 el galeón almirante de la flota del capitán-general Don Francisco del Corral, sale de Cádiz con un total de 108 marineros el 19 de marzo, pero cinco menos ( 3 artilleros y 2 grumetes) del número de marineros registrados el 10 de marzo: porque también se ausentaban marineros en España antes de la

(15) En este apartado trataremos también a los soldados ausentes de los galeones aunque no conocemos sus procedencias. Estas procedencias sí se pueden encontrar entre los Papeles de Armada de la sección de la Contratación del AGI. Una identificación de estas procedencias espera a un investigador. A pesar de esta omisión justificamos la incorporación de los soldados porque las fuentes de la que disponemos - AGI, Escribania, leg. 967 (Resultados de las residencias a las flotas y armadas de Indias) - no hacen en muchas ocasiones una distinción clara de qué grupo de tripulantes, soldados o marineros se trata. 
salida; generalmente después de haber recibido las primeras pagas. Llega a Cartagena el 20 de mayo, curiosamente con 110 marineros, al parecer ha recuperado a dos artilleros. Sale de Cartagena el 24 de junio con sólo 89 tripulantes: se habían ausentado cinco artilleros, cinco marineros y once grumetes. En Portobelo recupera parte de la tripulación porque salen de allí el 3 de agosto con 95 para ir de nuevo a Cartagena. De allí sale a España el 22 de agosto con una tripulación de 102 marineros (16). Parte de los tripulantes ausentes se recuperan con otros, aunque no nos explican de dónde venían y por qué razón están allí. Parece probable que se pudiera recuperar parte de la tripulación de la población marinera flotante que había en cada puerto americano (17).

Al avanzar el siglo XVII se registró un aumento en las ausencias de los marineros y soldados de los galeones (18). En 1616, por ejemplo, los galeones de la flota de Tomás del Arrazpuru a Tierra Firme, que se componía de cinco galeones y tres pataches, huyeron en total 99 marineros. En los puertos murieron cuatro marineros y en la mar, en total, diez. El mayor número de huidos lo encontramos entre los grumetes, en total 53: 23 se quedaron en Cartagena, 16 en Portobelo y 14 en La Habana. De los marineros huyeron en total 27, de los oficiales 15 y de los pajes sólo 4. El número de marineros que se declararon enfermos es relativamente bajo, en total 24 (19). Parece que declararse

(16) AGI, Contratación, leg. 67A, n 1, Ramo 2.

(17) AGI, Contratación, leg. 86B. Nueva Vera Cruz, 1 de mayo de 1620. "El señor general don Lope de Hozes y Cordoba dixo que atento a que de las naos capitana y almiranta, desta flota del cargo de su merced se an muerto e ydo y ausentado muchos marineros y grumetes de los que binieron en ellas de Castilla y es necesario llevar las dichas naos de buelta de biaxe con mas numero de marineros de los que en ellas binieron atento a los malos temporales y borrascas que de hordinario suele aber y a ques hordinario llevar en la dicha nao capitana dose marineros mas de el numero que truxo y dies de la nao almiranta, y para buscarlos que convengan ansi para cumplir el numero que de Cartagena binieron como para los de mas que se an de recevir es menester echar vandos con las caxas de guera por esta zivdad y puerto para que todos los marineros de las naos que binieron al traves de los demas questuvieron en el sin comodo parescan ante su merced y para questo y lo demas que conviene al serbizo de su majestad se haga mando se llame a junta y consejo de las casas de la morada de su merced al señor almirante y los capitanes Francisco de Torres y Francisco de Axpi dueños de las dichas naos". Este bando muestra que en los puertos de las Indias había una población flotante de marineros que se podían reclutar cuando viniera al caso.

(18) Fernando Serrano Mangas: Armadas y flotas de la Plata, Madrid, 1989. págs. 326-333.

(19) AGI, Contratación, leg. 2.985, fos. 118-121. 
enfermo como primer paso para llegar a tierra y huir posteriormente del hospital ya no era el camino preferido.

Si miramos estas cifras por galeón podemos darnos cuenta de las dificultades que tenían los oficiales para frenar las huidas. Las huidas se producen esporádicamente de cada galeón cuando tomamos en consideración el número de días que estaba en los puertos. Entre las medidas que los capitanes-generales de la flota tenían que tomar en los puertos de llegada en América, estaban instalar una guardia de la costa, ordenar que todos los marineros y soldados durmieran a bordo y sólo permitir bajo licencia la salida de la nao. Medidas, sin embargo que no podían sofocar la deserción de la tripulación. También se veían defraudadas estas medidas por los propios capitanes de las compañías que alistaron pasajeros disfrazados como soldados y por los propios maestres entre sus marineros.

CUADRO 6. MARINEROS AUSENTES DE LA FLOTA

DE TOMAS DE ARRAZPURU DE 1616

CARTAGENA DE INDIAS

\begin{tabular}{|c|c|c|c|c|c|c|c|c|c|}
\hline $\begin{array}{l}\text { Galeones }{ }^{1} \\
\text { Rango 2 }\end{array}$ & a & $\mathrm{b}$ & c & d & e & $\mathrm{f}$ & $\mathrm{g}$ & $\mathrm{h}$ & TOTAL \\
\hline \multicolumn{10}{|l|}{ Oficiales } \\
\hline Huidos & - & 2 & 1 & - & - & - & 1 & 6 & 10 \\
\hline Enfermos & 2 & 1 & - & - & - & - & - & - & 3 \\
\hline Muertos & - & - & - & - & - & - & - & - & - \\
\hline \multicolumn{10}{|l|}{ Marineros } \\
\hline Huidos & - & - & - & - & 2 & 1 & - & 4 & 7 \\
\hline Enfermos & 1 & - & 1 & 1 & - & - & - & - & 3 \\
\hline Muertos & - & - & - & - & - & - & - & - & - \\
\hline \multicolumn{10}{|l|}{ Grumetes } \\
\hline Huidos & 4 & 1 & 1 & 2 & 3 & 6 & 2 & 4 & 23 \\
\hline Enfermos & 2 & - & - & - & 1 & - & - & - & 3 \\
\hline Muertos & - & - & - & - & - & - & - & - & - \\
\hline \multicolumn{10}{|l|}{ Pajes } \\
\hline Huidos & - & - & - & - & - & - & - & - & - \\
\hline Enfermos & - & - & - & - & - & - & - & - & - \\
\hline Muertos & - & - & - & - & - & - & - & - & - \\
\hline
\end{tabular}


Cuadro 6.

(continuación)

\section{PORTOBELO}

Galeones ${ }^{1}$

Rango 2
a b
d
e $f$
g h
TOTAL

\begin{tabular}{llllllllll}
\hline Oficiales & 1 & - & - & - & 2 & - & 1 & - & 4 \\
Huidos & - & - & - & - & - & - & - & - & - \\
Enfermos & - & - & - & - & - & - & - & - & - \\
Muertos & - & - & -
\end{tabular}

\section{Marineros}

Huidos

Enfermos

Muertos

$$
\begin{array}{lllllllll}
2 & 2 & - & 1 & 1 & - & 1 & - & 7 \\
1 & - & - & 1 & - & - & - & - & 2
\end{array}
$$

Grumetes

$\begin{array}{llllllllll}\text { Huidos } & 3 & 3 & 2 & 3 & 3 & - & 2 & - & 16 \\ \text { Enfermos } & - & - & - & - & - & - & - & - & - \\ \text { Muertos } & - & - & 1 & - & - & - & - & - & 1\end{array}$

\section{Pajes}

$\begin{array}{llllllllll}\text { Huidos } & 1 & - & - & 1 & - & - & - & - & 2 \\ \text { Enfermos } & 1 & - & 1 & - & 1 & - & - & - & 3 \\ \text { Muertos } & - & - & - & - & - & - & - & - & -\end{array}$

\section{LA HABANA}

\section{Oficiales}

Huidos

Enfermos

Muertos

$$
\begin{array}{lllllllll}
- & - & - & 1 & - & - & - & - & 1 \\
1 & 2 & - & - & - & - & - & - & 3 \\
- & 1 & - & - & 1 & - & - & - & 2
\end{array}
$$

\begin{tabular}{llllllllll}
$\begin{array}{l}\text { Marineros } \\
\text { Huidos }\end{array}$ & 4 & 2 & 2 & 2 & 1 & 1 & 1 & - & 13 \\
Enfermos & - & - & - & - & - & - & - & - & - \\
Muertos & - & - & - & - & - & - & - & - & - \\
\hline
\end{tabular}

\section{Grumetes}

Huidos

Enfermos

Muertos

$\begin{array}{rrrrrrrrr}5 & 3 & - & 2 & 3 & - & - & 1 & 14 \\ 2 & - & 2 & 1 & - & - & - & - & 5 \\ - & - & - & - & - & - & - & - & -\end{array}$




\section{LA HABANA}

\begin{tabular}{|c|c|c|c|c|c|c|c|c|c|}
\hline $\begin{array}{l}\text { Galeones }{ }^{1} \\
\text { Rango }^{2}\end{array}$ & $\mathbf{a}$ & $\mathrm{b}$ & c & $d$ & e & f & $\mathrm{g}$ & h & TOTAL \\
\hline \multicolumn{10}{|l|}{ Pajes } \\
\hline Huidos & - & - & 1 & - & 1 & - & - & - & 2 \\
\hline Enfermos & - & - & 2 & - & - & - & - & - & 2 \\
\hline Muertos & - & - & - & 1 & - & - & - & - & 1 \\
\hline $\begin{array}{l}\text { Total } \\
\text { huidos }\end{array}$ & 20 & 13 & 7 & 12 & 16 & 8 & 8 & 15 & 99 \\
\hline $\begin{array}{l}\text { Total } \\
\text { Enfermos }\end{array}$ & 10 & 3 & 6 & 3 & 2 & - & - & - & 24 \\
\hline $\begin{array}{l}\text { Total } \\
\text { muertos }\end{array}$ & - & 1 & 1 & 1 & 1 & - & - & - & 4 \\
\hline
\end{tabular}

Fuente: AGI, Contratación, leg. 2985, fos. 118-121.

1 Galeones: $a=$ Capitana; $b=$ Almiranta; $c=$ Nuestra Señora de la Vitoria; $\mathrm{d}=$ Nuestra Señora de Atocha; e = Nuestra Señora del Rosario; Pataches; $\mathrm{f}=$ San Francisco, $\mathrm{g}=$ San Juan de Regla; $\mathrm{h}=$ Nuestra Señora de Begoña.

2 Entre los oficiales se incluyen también a los que hemos llamado los suboficiales.

Este flujo migratorio hacia las Indias, como consecuencia de las flotas semestrales y reforzada por la necesidad de proteger estas flotas con la Armada, cambió por completo la estructura de la población española en América. Dentro de la emigración legal española la proporción entre hombres y mujeres era alrededor de una mujer por cada tres a cuatro hombres. La emigración procedente de las naos era exclusivamente masculina. No hemos encontrado casos de mujeres disfrazadas de marinero como ocurrió en las flotas holandesas a las Indias Orientales, donde han podido localizarse unos cien casos (20). A veces el número de ausencias de marineros y grumetes registradas en los galeones, junto a las de los soldados sobrepasa al número de

(20) J. R. Bruidn, F. S. GaAstra y I. Schofer: Dutch-Asiatic Shipping in the 17th and 18th Century, I, La Haya, 1987. pág. 148. 
emigrantes legales masculinos (21). Aunque no se conocen datos para todos los años, el Cuadro 7 ilustra muy bien la importancia númerica de estas ausencias.

CUADRO 7. LAS AUSENCIAS DE MARINEROS Y SOLDADOS EN INDIAS, 1598-1610

\begin{tabular}{cccc}
\hline Destino/año & Nueva Eıspaña & Tierra firme & Total \\
\hline 1598 & - & - & - \\
1599 & Muchas & Muchas & Muchas \\
1600 & - & - & - \\
1601 & - & - & - \\
1602 & - & 358 & 358 \\
1603 & 256 & 226 & 482 \\
1604 & - & - & - \\
1605 & 42 & 550 & 592 \\
1606 & 187 & 394 & 581 \\
1607 & - & 198 & 303 \\
1608 & - & -159 & 168 \\
1609 & 166 & 159 & 286 \\
1610 & 127 & 2.188 & 2.966 \\
\hline TOTAL & 778 & & \\
\hline
\end{tabular}

Fuente: AGI, Contratación, 2964; Escribanía 967.

Estas cifras pueden estar algo sobrevaloradas porque los generales podían alistar pasajeros, que iban con licencia real a las Indias, en plazos de soldado desde ocho días antes de la salida de la flota cuando hubiera falta de gente de guerra. A estos pasajeros no se les daba paga sino sólo la ración diaria y por supuesto, no se les cobraba el pasaje (22). Es bastante probable que entre

(21) Ruke P. JaCoBs: "Emigration from Seville, 1550-1650" en I. Altman, y J. HoRN (eds.), "To Make America": European Emigration in the Early Modern Period. University of California Press, Berkeley, Los Angeles, Oxford 1991, págs. 59-84.

(22) Veitia Linaje [5]. Lib. I, cap. XXIX, págs. 225-226. En 1616 figura en la lista de soldados de la nao almiranta de la flota a Tierra Firme el nombre de un tal Manuel Francisco, natural de Sevilla, tachado. Se inculpan al escribano real de la flota, Cristóbal Chamorro, que había falsificado la lista. Por una declaración del sargento mayor Juan Pérez Vídano, sin embargo, resulta que Manuel Francisco era un pasajero que iba con su mujer y dos hijos pequeños a Tierra Firme pero que se había alistado por soldado recibiendo las raciones [AGI, Contratación, leg. 83D]. 
estos soldados ausentes figuren algunos pasajeros legales que se quedaron en Indias sin que incurriesen en falta alguna.

El problema de esta población marinera y militar, que se quedó atrás, es que no sabemos dónde iba a establecerse. Sólo podemos saber en qué puerto abandonaron el navío. Las características de esta población resultan más claras. Es exclusivamente masculina, tiene edades de entre 16 a 25 años mayoritariamente y ha servido preferentemente en los rangos de marinero y grumete o de soldado raso. Tanto en el caso de los grumetes como en el de los soldados es dudoso si, de veras, tenía experiencia marítima o militar anterior, parece más bien que se alistaron en los barcos porque no tenían otro empleo en su oficio original (23). Pasar a Indias les proporcionaba tentar las posibilidades que las Indias les podían brindar. Si estas ausencias se distribuyeran proporcionalmente entre las procedencias geográficas de los tripulantes, serían los andaluces y los portugueses los principales pobladores ilegales de las Indias.

La mayor competencia de otras naciones europeas en la $\mathrm{Ca}$ rrera de Indias obligó a España a protegerla con una Armada de Guardia contra los ataques de franceses, holandeses e ingleses. Esta misma protección era responsable de una corriente inoportuna de migraciones laborales a las Indias que, por un lado, reforzó la presencia española allí y por otro, por las características demográficas mismas de la población marinera y militar, se responsabilizó de un mestizaje más acusado entre la población española y la indígena porque alteró la proporción entre los sexos dentro de los inmigrantes españoles.

(23) En 1603 el grumete Juan García, natural de Pozuelo en la provincia de Cáceres, intentó huir del navio del maestre Gaspar Vera de Maldonadø en Portobelo pero le capturaron en la sierra de Capira. Al preguntar qué oficio tenía, respondió que era hombre del campo [AGI, Contratación, leg. $68 \mathrm{C}$, Ramo 3, $\mathrm{n}^{2}$ 3].

El 18 de mayo de 1613 se capturaron en Cartagena a Juan Gómez, natural de Málaga, soldado en el galeón "Nuestra Señora del Rosario" que resultó ser tejedor de terciopelo. Otro soldado del mismo galeón dijo ser arriero [AGI, Contratación, leg. 599, Ramo 1, $\mathrm{n}^{\mathcal{2}}$ 2] Estos dos ejemplos pueden aumentarse mucho más]. 